\title{
ABOUT THE POSSIBILITY OF APPLICATION OF LASER VACUUM WELDING FOR THE INTEGRATION OF ELEMENTS OF HEAT-PROTECTIVE STRUCTURES FROM POWDER MATERIALS
}

\author{
Walid Alnusirat \\ Department of Industrial Engineering \\ Al-Balqa Applied University \\ 1911 Al-Salt, Amman, Jordan, P.O.box 206 \\ Alexandr Salenko \\ Department of Machine Tools and Mahinery Systems \\ National Technical University of Ukraine «Igor Sikorsky Kyiv Polytechnic Institute» \\ 37 Peremohy ave., Kyiv, Ukraine, 03056 \\ Olga Chencheva $₫$ \\ Department of Industrial Engineering ${ }^{l}$ \\ chenchevaolga@gmail.com \\ Sergii Shlyk \\ Department of Manufacturing Engineering ${ }^{1}$ \\ Irina Gusarova ${ }^{2}$ \\ Alexandr Potapov ${ }^{2}$ \\ ${ }^{1}$ Kremenchuk Mykhailo Ostrohradskyi National University \\ 20 Pershotravneva str., Kremenchuk, Ukraine, 39600 \\ ${ }^{2}$ Yuzhnoye Design Office \\ 3 Kryvorizka str., Dnipro, Ukraine, 49008
}

$\triangle$ Corresponding author

\section{Abstract}

The results of studying the process of laser vacuum welding of elements of heat-shielding panels made of heat-resistant dispersion-strengthened powder materials Ni-20Cr-6Al-Ti- $\mathrm{Y}_{2} \mathrm{O}_{3}$ of increased strength are presented. Such materials can be used to create ultralight heat-shielding panels, which are systems integrated on the surface of aircraft from typical modules of a cellular structure.

Technical solutions of heat-insulating modules are considered, which are a cellular (honeycomb) structure consisting of two plates with a thickness of 0.1 to $0.14 \mathrm{~mm}$, inside which there is a thin honeycomb filler. It is shown that the small thickness of the plates and the complexity of integrating the elements into a single system significantly impair the formation of a strong connection of such elements and do not allow the direct use of the known methods of diffusion welding or vacuum brazing.

It has been established that laser welding of elements of heat-shielding structures in vacuum provides satisfactory strength of the structure of the heat-shielding element as a whole. Local heating at certain points prevents deformation of the parts to be joined during the welding process. The use of a pulsed Nd:Yag laser with a power of 400-500 W, operating in the frequency range of 50-200 Hz, allows welding with or without a filler powder. It was found that the use of filler additives practically does not affect the mechanical properties of the welded joint, however, it reduces the melt zone, while increasing the density of the welded joint.

Based on the results obtained, it was concluded that it is possible to use laser vacuum welding for the integration of thin elements of heat-shielding modules. It is shown that a satisfactory joint strength is achieved by ensuring high cleanliness of the surfaces of elements before welding, maintaining a high vacuum (less than $10^{-2} \mathrm{~Pa}$ ) and rational thermal loading of the surfaces of the elements to be integrated.

The use of the proposed process makes it possible to obtain a stronger and denser seam in comparison with the known methods of soldering multicomponent powder dispersion-strengthened materials.

Keywords: laser vacuum welding, strength of welded joint, dispersion-strengthened alloys, heat-shielding structures.

DOI: $10.21303 / 2461-4262.2021 .001998$ 


\section{Introduction}

Designs of heat-shielding panels for reusable spacecraft with an outer metal plate are being actively developed by leading experts from many countries [1, 2]. Today it is becoming evident that the most effective thermal protection consists of individual tile-modules attached to the hull of the spacecraft. Such protective tiles typically consist of a top and bottom plate with a honeycomb core in between. The tiles are mechanically attached to the hull of the spacecraft. At the same time, tiles can also be integrated into a single system and separately from the body, with subsequent placement on surfaces requiring thermal protection.

Such integration requires welding or soldering of the plates simultaneously with the installation of a U-shaped elastic heat-compensating element, as well as additional fasteners (legs) that ensure fastening of the thermal protection to the surface of the spacecraft (Fig. 1).

Promising materials used to create heat-shielding systems are multicomponent powder materials based on (Ni-Cr), in particular, a five-component powder composite material consisting of metallic $(\mathrm{Ni}-\mathrm{Cr})$, intermetallic $\left(\mathrm{Al}-\mathrm{Ni}_{3}\right)$ and oxide $\left(\mathrm{Y}_{2} \mathrm{O}_{3}\right)$ phases. However, its application, despite numerous advantages, is difficult due to the exceptional complexity of welding or brazing $[3,4]$ of non-rigid thin structural elements.

So, according to [4], when brazing structures in a vacuum furnace, prolonged exposure to high temperatures leads to the appearance of residual thermal deformations of the processed parts (Fig. 2), causing their warpage. The stability of the strength and density indicators of the weld is significantly reduced. The recommendation to solder in one setup is applicable only for attaching the upper and lower plates, as well as the U-shaped insert between them.

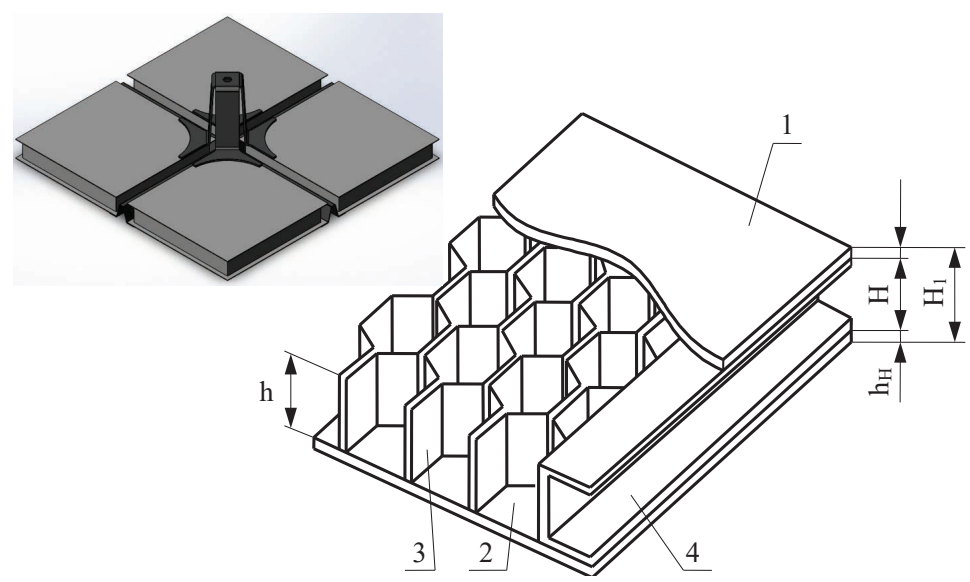

Fig. 1. Typical heat-insulating systems of spacecraft and their design: 1 - top plate; 2 - bottom plate; 3 - honeycomb filler; 4 - side plate

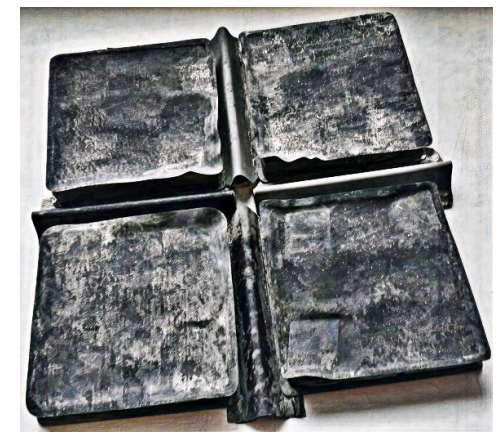

Fig. 2. Residual thermal deformations of workpieces

The efficiency of the use of lasers in welding and related processes (in the processing of the surface layer) is considered in a number of works [5-8]. In [5], the features of using gas lasers for welding non-ferrous metals are analyzed, in [6] - for welding alloyed, heat-resistant and diffi- 
cult-to-machine materials. Work [7] shows the prospects for using pulsed lasers for welding special steels. At the same time, some researchers believe that a higher quality of the formation of permanent joints is provided under conditions of high or low vacuum [8]. This is especially true for cases of integration of elements prone to embrittlement and warping.

Porosity and low bond strength for Ni-based alloys is one of the important problems due to the high sensitivity of $\mathrm{Ni}$ to the content of impurities in the material (P, S) and an increase in the concentration of dissolved gases in the weld or spot. «Hydrogen disease» occurs due to a sharp decrease in the solubility of $\mathrm{O}_{2}, \mathrm{H}_{2}, \mathrm{H}^{+}$and $\mathrm{CO}$ with a decrease in the temperature of the molten liquid metal and with a limitation of the possibility of removing gases during the crystallization of the weld pool.

However, the greatest degree of pore formation is associated with the saturation of the molten bath with N, especially in the presence of oxygen. For heat-resistant alloys, the weld material is prone to embrittlement and the formation of a network of microcracks, which is due to the appearance of the Ni-NiO eutectic $\left(T_{p l}=1438^{\circ} \mathrm{C}\right)$, distributed outside the crystallites during the cooling of the weld pool. This reduces the strength of the grain boundaries, makes the seam not only porous, but also brittle.

From this point of view, the prospect of using a vacuum chamber to ensure reliable protection of the welding zone from the atmosphere, as well as the use of high-purity filler materials for brazing or laser welding, is reasonable and reasonable.

For the manufacture of thermal protection models, it is of interest to overlap and butt welding of thin sheet elements of heat-resistant dispersion-strengthened material Ni-20Cr- $6 \mathrm{Al}-\mathrm{Ti}-\mathrm{Y}_{2} \mathrm{O}_{3}$ by methods of local (high intensity) heating of the contact zone using a laser.

The aim of the work is to study the possibility of creating reliable permanent joints from thin-leaf $(0.1 \ldots 0.14 \mathrm{~mm})$ billets $\mathrm{Ni}-20 \mathrm{Cr}-6 \mathrm{Al}-\mathrm{Ti}_{-} \mathrm{Y}_{2} \mathrm{O}_{3}$ in contact with each other.

\section{Materials and methods}

To integrate the elements into a single design of the heat protection module, it is necessary to perform laser overlap and butt welding. The process diagram is shown in Table $\mathbf{1 .}$

Heating of the surface by the laser, provided that the radiation intensity is distributed at the laser output window in accordance with the Gaussian law:

$$
I(w)=I_{0} \exp \left(-\omega^{2} / w_{G}^{2}\right)
$$

$I_{0}$ - the radiation intensity on the beam axis; $w$ - current radius; $w_{G}$ - radius at which the radiation intensity decreases by a factor of $e$, and, taking into account:

will be described by the equation:

$$
\frac{\partial T}{\partial t}=\alpha\left(\frac{\partial^{2} T}{\partial x^{2}}+\frac{\partial^{2} T}{\partial y^{2}}+\frac{\partial^{2} T}{\partial z^{2}}\right)
$$

$$
T(x, z, t)=\frac{q(x) r^{2}}{\lambda}\left(\frac{a}{\pi}\right)^{1 / 2} \int_{0}^{t} \frac{P(t-\tau) \exp \left[\frac{z^{2}}{4 a t}-\frac{x^{2}}{4 a \tau}\right]}{\sqrt{\tau}\left(4 a \tau+r^{2}\right)} \mathrm{d} \tau
$$

where $\lambda$ - coefficient of thermal conductivity; $a$ - coefficient of thermal conductivity; $t$ - current time; $P$ - power of laser radiation.

Boundary conditions on the heated surface:

$$
-\left.k \frac{\partial T}{\partial z}\right|_{z=0}=q(x, y, t),
$$

where

$$
q=q=q_{0}(1-R)
$$

$q_{0}$ - the radiation power density; $R$ - surface reflection coefficient; $k$-coefficient of thermal conductivity of the material. 
To determine the average temperature on the surface of a semi-infinite body at a point with coordinates $(x, y, z)$ heated by a laser beam moving at a speed $v$, one can use the relation coefficient of thermal conductivity; $a$ - coefficient of thermal conductivity; $t$ - current time; $P$ - power of laser radiation.

$$
\bar{T}=\frac{16}{\sqrt{\pi}} \int_{0}^{\infty} \frac{1}{\sqrt{\left(c^{\prime 2}+\tau^{2}\right)\left(b^{\prime 2}+\bar{\tau}^{2}\right)}} \exp \left[-\frac{\left(2 \bar{x}^{\prime 2}+\bar{v}^{\prime} \tau\right)^{2}}{4\left(\bar{c}^{2}+\bar{\tau}^{2}\right)}-\frac{\bar{y}^{2}}{\bar{b}^{2}+\bar{t}^{2}}-\frac{\bar{z}^{2}}{\bar{t}^{2}}\right] \mathrm{d} \tau
$$

moreover,

$$
\overline{\mathrm{v}}=\frac{\mathrm{v}_{r}}{2 a} ; \bar{x}^{\prime}=\frac{x}{r} ; \bar{y}^{\prime}=\frac{y}{r} ; \bar{z}^{\prime}=\frac{z}{r} ; \bar{c}^{\prime}=\frac{c}{r} ; \bar{b}^{\prime}=\frac{b}{r} ; r^{2}=c b
$$

$A_{0}$ - reflective (absorption) ability of the material of the workpiece; $P$ - power of laser radiation; $b, c$ - parameters of the density (power) distribution of laser radiation.

For continuous heating, the temperature change on the irradiation plane is determined by the ratio:

$$
\begin{aligned}
& T(x, y, z, t)=\frac{P}{\pi \frac{1}{2} \rho c^{0}} \int^{t} \frac{e^{\frac{(x-v(t-z))^{2}}{4 \alpha \tau+A^{2}} \frac{y^{2}}{4 \alpha \tau+B^{2}}}}{\left[\left(4 \alpha \tau+A^{2}\right)\left(4 \alpha \tau+B^{2}\right) \alpha \tau\right]^{1 / 2}} \times \\
& \times\left[e^{-\frac{z^{2}}{4 \alpha \tau}}-\eta(\pi \alpha \tau)^{1 / 2} \operatorname{erfc}\left(\frac{z}{2(\alpha \tau)^{1 / 2}}+\eta(\alpha \tau)^{1 / 2}\right) \times e^{\eta z+\eta^{2} \alpha \tau}\right] d \tau,
\end{aligned}
$$

where $x, y, z$ - coordinates; $t$ - time; $\eta$ - coefficient of heat transfer from the surface of the workpiece; $\alpha$ - thermal conductivity coefficient; $A$ and $B$ - major and minor axes of the heating spot; $P=\pi q A B$ - power of the emitter, and the distribution of heat will occur in the plane of the plates of limited thickness.

The use of a pulsed laser requires taking into account the redistribution of temperature in the period between pulses,

$$
T(t)=T_{\max }-\frac{q_{l} \delta}{\lambda}\left[\frac{2}{\sqrt{\pi}} \frac{\sqrt{a(t-\tau)}}{\delta}+\exp \left(\frac{a(t-\tau)}{\delta^{2}}\right) \operatorname{erfc}\left(\frac{\sqrt{a(t-\tau)}}{\delta}\right)\right],
$$

where $\delta$ - depth of heating; $q_{1}=f(f \mathcal{c}, p, t)$.

The process of thermal conductivity in the volume of the material bounded by the region $\Omega$, with the surface $\partial \Omega$, is described by: a scalar temperature field $T=T(P, t)$; vector field of the heat flux $q=q(P, t), P=\{(x, y, z)\} \in \Omega$, scalar field with specific thermal $e=e(T)$.

The boundary conditions on the outer surfaces for $\tau>0$ will be as follows:

$$
\left\{\Gamma_{1}:-\lambda \frac{\partial t}{\partial n}=q_{r} ; \Gamma_{2}: \frac{\partial t}{\partial n}=0 ; \Gamma_{3}:-\lambda \frac{\partial t}{\partial n}=\alpha\left(t-t_{\text {medium }}\right) ;\right.
$$

Conditions at the contact boundary $\Gamma_{4}$ at $\tau_{0}$ :

$$
\left\{\begin{array}{l}
\left.t\right|_{\Gamma_{\overline{4}}^{-}}=\left.t\right|_{\Gamma_{4}^{+}}, \\
-\left.\lambda_{-} \frac{\partial t}{\partial n}\right|_{\Gamma_{\overline{4}}^{-}}=\left.\lambda_{+} \frac{\partial T}{\partial t}\right|_{\Gamma_{4}^{+}},\left\{\begin{array}{l}
t<t_{m}-\frac{\Delta t}{2}, \lambda_{1}(t)=\lambda_{s} ;\left[c_{p}(t) \rho(t)\right]_{1}=c_{p s} \rho_{s} ; \\
t_{m}-\frac{\Delta t}{2} \leq t \leq t_{m}+\frac{\Delta t}{2}, \lambda_{1}(t)=\lambda_{s}+\frac{\lambda_{m}-\lambda_{s}}{\Delta t}\left(t-t_{m}+\frac{\Delta t}{2}\right) \\
{\left[c_{p}(t) \rho(t)\right]_{1}=c_{p s} \rho_{s}+\frac{c_{p m} \rho_{m}-c_{p s} \rho_{s}}{\Delta t}\left(t-t_{m}+\frac{\Delta t}{2}\right)+\frac{L_{f}}{\Delta t}} \\
t>t_{m}+\frac{\Delta t}{2}, \lambda_{1}(t)=\lambda_{m} ;\left[c_{p}(t) \rho(t)\right]_{1}=c_{p m} \rho_{m} ;
\end{array}\right.
\end{array}\right.
$$


where $n$ - normal to the surface; $q_{r}$ - power density; $\alpha$ - heat transfer coefficient; $\Gamma_{1}-$ irradiated surface; $\Gamma_{2}-$ axial symmetry surface; $\Gamma_{3}-$ contact surface with the external environment; $\Gamma_{4}-$ contact boundary of two welded elements.

The motion of the phase boundaries can be set based on the one-dimensional non-stationary heat conduction equation $\frac{\partial^{2} T}{\partial z^{2}}=\frac{1}{D} \frac{\partial T}{\partial t}$, where $D=K /(\rho c)-$ thermal diffusivity.

The dimensionless velocity of the phase boundary movement depending on the dimensionless time for the temperature $T(z, t)$ with the boundary conditions on the moving boundary $z=\lambda(t)$ takes the form:

$$
\frac{d \xi}{d t}=\left[1+\varepsilon\left\{\frac{1}{2} \operatorname{erfc}\left(\frac{\tau^{1 / 2}}{2}\right)-\frac{1}{(\pi \tau)^{1 / 2}} e^{-\frac{\tau}{4}}\right\}\right] \frac{2}{\pi}\left\{1+\frac{\varepsilon}{\pi \tau^{1 / 2}}\right\} \arcsin \left\{\left(1-\frac{\pi \varepsilon^{2}}{4 \tau}\right)^{1 / 2}\right\}
$$

The static formulation of the problem allows one to estimate the expected size of the melt spot, taking into account the thermophysical properties of the elements being welded.

In practice, the obtained equations are rather difficult to use, since a significant number of thermal engineering coefficients for a powder material is rather difficult to determine, as are the contact conditions for a butt-welding scheme of plates. For the case of overlapping welding, equation (3) is difficult to use due to the limited area of contact.

To determine the rational conditions for the thermal effect of the laser on the integrated plates, the process of thermal loading of the surface under high vacuum conditions was simulated. In the simulation, it was assumed that the heating of the plate surface alternated with the propagation of heat into the material at the moment of the absence of a pulse.

Welding modes are given under the corresponding schemes in Table 1, and the obtained temperature fields are in the second column of the Table $\mathbf{1 .}$

The obtained pictures of the temperature distribution on the surface and over the cross-section of the workpieces in the contact zone made it possible to establish the time (and, consequently, the number of pulses), during which the temperature in the center of irradiation above $1175{ }^{\circ} \mathrm{C}$ (the temperature of phase transformations), as well as the temperature of formation of the melt bath, will be reached. over $1460{ }^{\circ} \mathrm{C}$.

It was found that for a Nd:YaG laser operating at a frequency of $125 \mathrm{~Hz}$ with a power of $0.4 \mathrm{~kW}$, the heating time of the welding point of a $0.8 \mathrm{~mm}$ diameter part should not exceed 120-150 ms. Such calculations are approximate for a welding station built on the basis of a VUP-5 universal vacuum station, the laser radiation into the working chamber of which was fed using a system of mirrors from a universal laser complex LSK-400-5 [9] (Fig. 3). During welding, the beam was focused in the plane of the upper integrated part. Positioning was carried out using an automated cross table of working movements, which provides welding at several points with different duration of the process. The latter ranged from $0.1 \mathrm{~s}$ to $0.15 \mathrm{~s}$; the exposure time of the weld point was provided by a mechanical interrupter. The movement between the welding points was carried out according to the program.

Mechanical tests of the finished samples were performed on a R-20 tensile testing machine equipped with an m-Daq ADC automated data collection system and means for displaying the diagram and loading conditions. The samples were tested at room temperature and at the expected operating temperature $\left(T=500 \ldots 600^{\circ} \mathrm{C}\right)$.

Placement of samples in a vacuum chamber is performed so that the weld pool is formed in a horizontal plane. Welding was carried out both without filler metal, and with those:

1) $\operatorname{VPr} 36[10]$ (composition $0.2 \% \mathrm{C} ; 8-10 \% \mathrm{Cr} ; 2.5-6.0 \% \mathrm{Al} ; 1.4-2.0 \% \mathrm{Mo} ; 2-5 \% \mathrm{Nb}$; $2-6 \% \mathrm{~W} ; 2.5-3.0 \% \mathrm{~B}$; the rest is $\mathrm{Ni}$ );

2) finely dispersed Ni powder ( $\mathrm{Ni} ; 5 \% \mathrm{~W} ; 1.0-1.5 \% \mathrm{~B})$.

The tests were carried out both for the material Ni-20Cr-6Al-Ti- $\mathrm{Y}_{2} \mathrm{O}_{3}$ and for other hightemperature alloys: YIPM-1200, YIPM-Ni-20Cr-3Al. The mechanical properties of materials are given in Table 2. Control over the weld condition and study of the material structure were carried out using a scanning electron microscope REM-106-I (Ukraine). 
Table 1

Simulation results of the vacuum welding process

No.

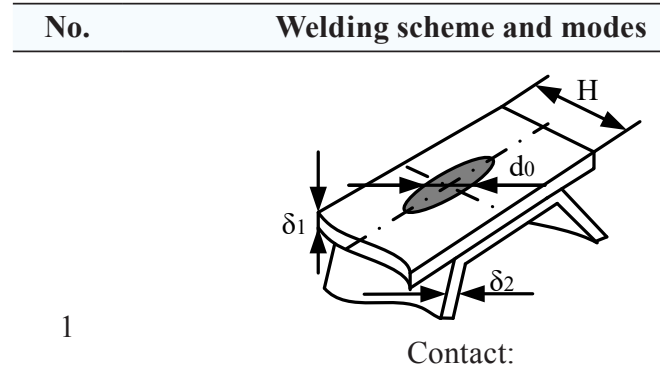

thickness: $\delta_{1}=0.14 \mathrm{~mm} ; \delta_{2}=0.14 \mathrm{~mm}$; $d_{0}=0.5 \mathrm{~mm} ; H=14.0 \mathrm{~mm}$; clamping force $-5 \mathrm{~N}$; beam power $-400 \mathrm{~W}$; pulse repetition rate $-125 \mathrm{~Hz}$; pulse energy $-8 \mathrm{~J}$

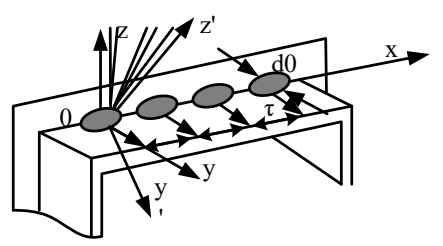

End:

thickness: $\delta_{1}=0.14 \mathrm{~mm} ; \delta_{2}=0.14 \mathrm{~mm}$; $d_{0}=2.5 \mathrm{~mm} ; H=14.0 \mathrm{~mm}$; clamping force $-20 \mathrm{~N}$; beam axis angle $-\pi / 4$ (coordinate system $X_{O} O Z_{1} Y_{1}$ ); beam power $-400 \mathrm{~W}$; pulse repetition rate $-125 \mathrm{~Hz}$; pulse energy $-8 \mathrm{~J}$
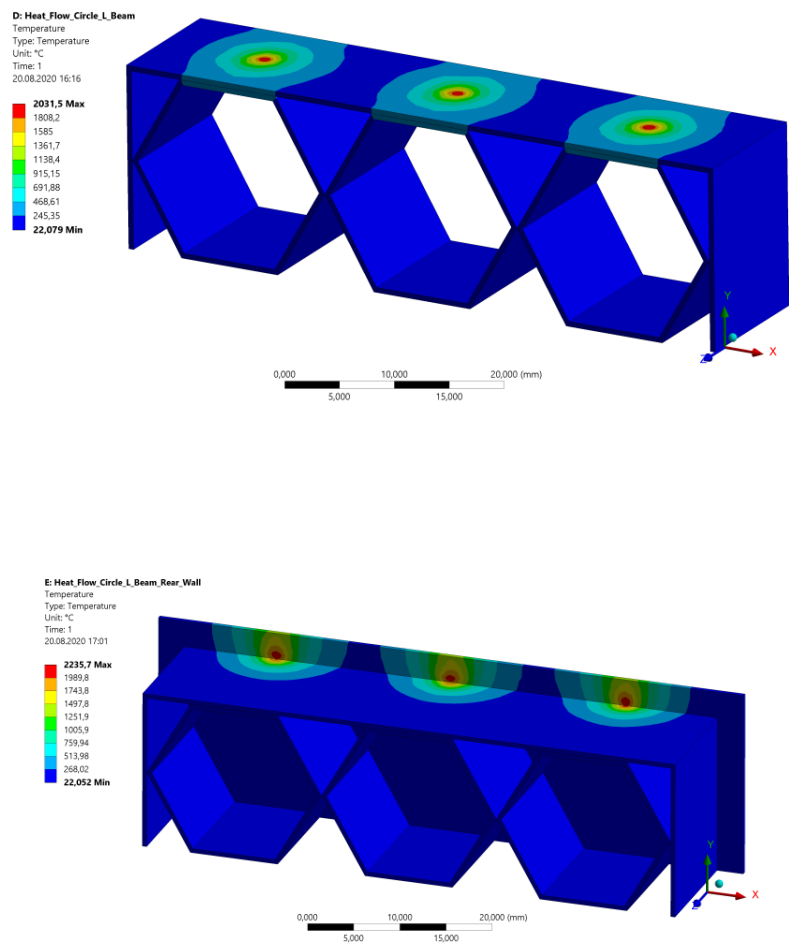

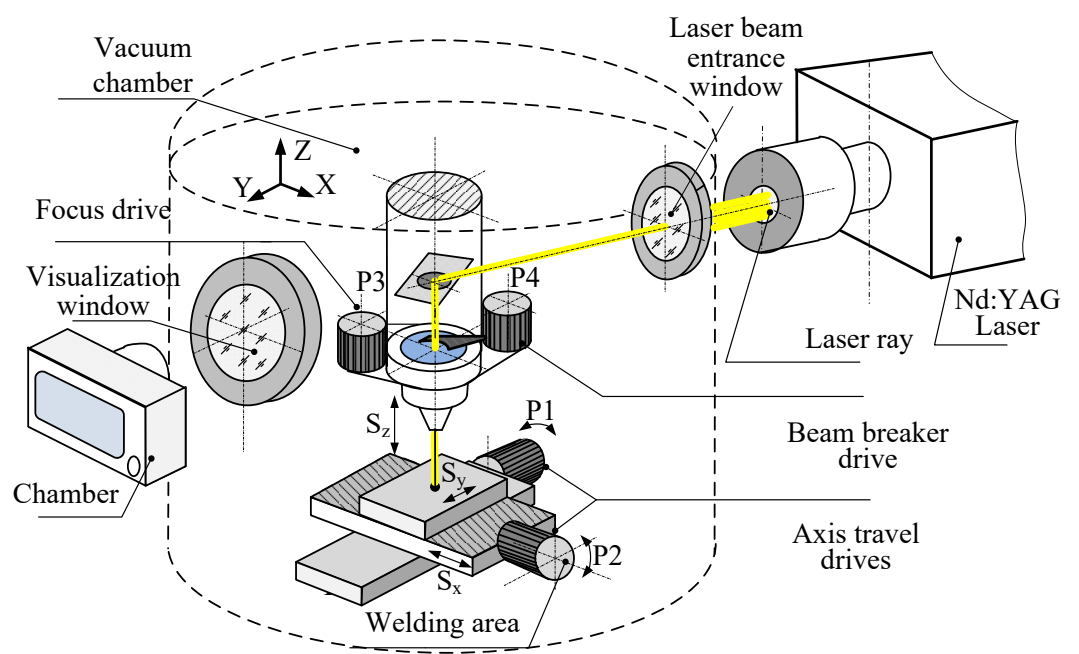

Fig. 3. The equipment used and the scheme of exposure of the beam to the surface

Thermal etching was used to identify the composition and structure of multicomponent alloys by scanning electron microscopy. The essence of the method was to obtain thin sections with a surface roughness of Ra $0.16 \mu \mathrm{m}$, followed by their heating to a temperature of $550{ }^{\circ} \mathrm{C}$ and holding for $12 \mathrm{~min}$.

The sections were made according to the standard technique, the material removal was less than $0.08 \mathrm{~mm}$, and there were no surface defects. The size of the irradiation zone, and, consequently, 
the welding zone was changed with the help of electromechanical focus adjustment, which made it possible to ensure the local heating of the surface from $0.27 \mathrm{~mm}$ to $1.8 \mathrm{~mm}$ in diameter.

Table 2

Mechanical properties of the used nichrome - based alloys

\begin{tabular}{|c|c|c|c|c|}
\hline Characteristic & $T,{ }^{\circ} \mathbf{C}$ & YIPM-1200 & YIPM-Ni ${ }_{20} \mathrm{Cr}_{3} \mathrm{Al}$ & 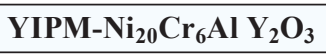 \\
\hline Aluminum content, $\%$ & - & - & 3.0 & $5.0-6.0$ \\
\hline Density, $\mathrm{m}^{3} / \mathrm{kg}$ & - & 8300 & 7950 & 7500 \\
\hline \multirow[t]{4}{*}{ Tensile strength, $\sigma_{b}, \mathrm{MPa} / \mathrm{MPa} / \mathrm{kg}$} & 20 & $738 / 0.09$ & $1020 / 0.136$ & $1005 / 0.134$ \\
\hline & 800 & $237 / 0.03$ & $542 / 0.07$ & 999 \\
\hline & 1100 & 45 & - & - \\
\hline & 1200 & - & 40 & 56 \\
\hline \multirow[t]{4}{*}{ Yield strength, $\sigma_{0.2}, \mathrm{MPa}$} & 20 & 364 & 624 & 760 \\
\hline & 800 & 228 & 457 & 687 \\
\hline & 1100 & 40 & - & - \\
\hline & 1200 & - & 35 & 51 \\
\hline \multirow[t]{4}{*}{ Elongation, $\delta \%$} & 20 & 36.5 & 21 & 12.9 \\
\hline & 800 & 36.7 & 18.1 & 2.0 \\
\hline & 1100 & 32.8 & 18 & - \\
\hline & 1200 & - & 18 & 22.3 \\
\hline
\end{tabular}

The composition of the elements of the connection zone, as well as adjacent areas, was studied. The study was carried out by the method of energy dispersive X-ray microanalysis.

\section{Results and discussion}

When preparing samples for welding (the formation of U-shaped elements, strips of honeycomb fillers), preliminary heat treatment was carried out - annealing in vacuum for 20 to 30 minutes at a temperature of 780 to $800^{\circ} \mathrm{C}$. Such annealing modes are recommended for work hardening of integrated elements made of $\mathrm{Ni}-\mathrm{Cr}$ alloy and subjected to plastic deformation. This made it possible to improve the structure of the processed elements and reduce the tendency of the material to interlayer cracking with the release of particles of coagulated material, which is characteristic of the powder components used in sintering (Fig. 4, $\boldsymbol{a}, \boldsymbol{b}$ ).

Without heat treatment, the workpieces were destroyed even with relatively small deformations.

The welding mode was selected based on the results of modeling temperature fields (Table 2) according to (4).
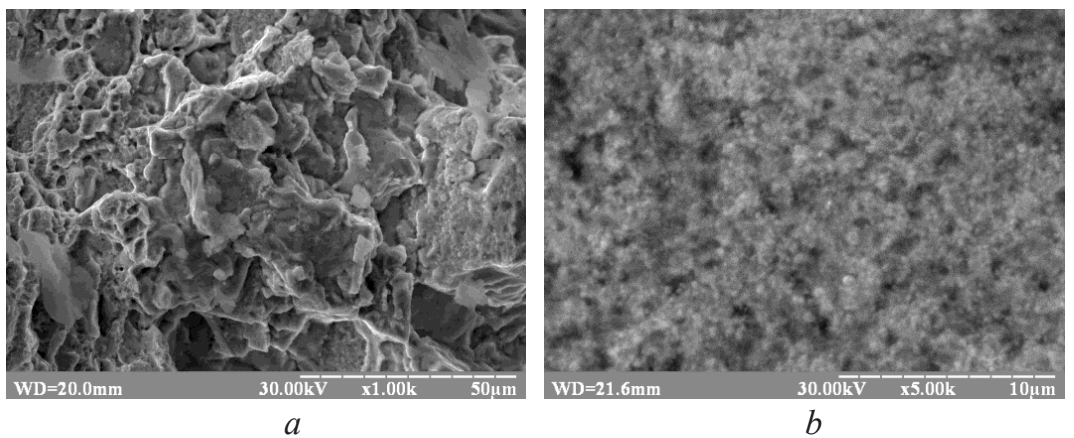

Fig. 4. Fracture of the workpiece $(0.4 \mathrm{~mm})$ during bending: $a$ - before heat treatment; $b$ - after heat treatment

Microelectronic analysis of the weld points showed that the weld pool was formed unevenly, the material splashed out of the weld pool and formed a rather large (up to $200 \mu \mathrm{m}$ ) droplet influx (Fig. 5). Almost all points had through penetration (which is due to the small thickness of the workpieces, $h=0.14-0.4 \mathrm{~mm}$ ), while the shape of the holes obtained differed from the correct 
geometric circle and amounted to $0.2-1.3 \mathrm{~mm}$. This is due to the fact that the used laser with a wavelength of $1062 \mathrm{~nm}$ with the specified pulse generation parameters is powerful enough to perform welding operations. In addition, the laser beam was introduced into the chamber through special windows equipped with silicate glass, since special phosphate glasses were not available. An attempt to form a seam with a linear feed motion somewhat improved the result, however, it was not possible to fully obtain stable seam parameters. The reason may also be the shutter used, the response time of which $(\tau=0.07 \mathrm{~s})$ is comparable to the duration of the laser action on the surface. There were no significant differences in the formed welding points for different alloys (YIPM-1200, YIPM-Ni ${ }_{20} \mathrm{Cr}_{3} \mathrm{Al}$, Ni-20Cr-6Al-Ti- $\mathrm{Y}_{2} \mathrm{O}_{3}$ ), however, for YIPM-1200, YIPM-Ni ${ }_{20} \mathrm{Cr}_{3} \mathrm{Al}$, burnthroughs and holes were less (no more than $0.3 \mathrm{~mm}$ ) diameter.

It was found that the low thermal conductivity of $\mathrm{Ni}$ and nickel alloys during welding leads to an increase in grain size and, as a consequence, to a decrease in the toughness and strength of the weld as a whole.

Attempts to carry out heat treatment aimed at preventing structural changes in the welding zone and in the near-welding zone are less effective than the introduction of melt modifier additives (Ti, Mo, Al) and limiting the welding energy per unit length. Prevention of the formation of $\mathrm{Ni}$-Al was carried out by sharp cooling (lasting from 3 to $5 \mathrm{~min}$ ) Of the samples after welding by blowing the vacuum chamber with argon cooled to a temperature of $-30 \ldots-20^{\circ} \mathrm{C}$.

Of interest is the result of studying the trace element composition of the welding zone with and without filler powder (Fig. 6, a). The analysis was carried out at three points - directly in the melt zone, in the near region of the weld, which was heated above $950{ }^{\circ} \mathrm{C}$, and on the bearing surface (Fig. 6, b).

Table 3 shows a comparison of the results obtained - laser welding and brazing in vacuum (both in a clean zone and using a filler powder of the APC type). The presence of a significant proportion of $\mathrm{C}$ is caused by carbon «poisoning» of the surface from the graphite tile of the table, which was used as a thermal insulation element together with ceramic plates of $\mathrm{Al}_{2} \mathrm{O}_{3}$. This is obvious if to neglect the insignificant proportion of $\mathrm{Na}, \mathrm{S}, \mathrm{Cl}, \mathrm{K}, \mathrm{Ca}$ detected during the analysis and present in parts of the vacuum chamber.

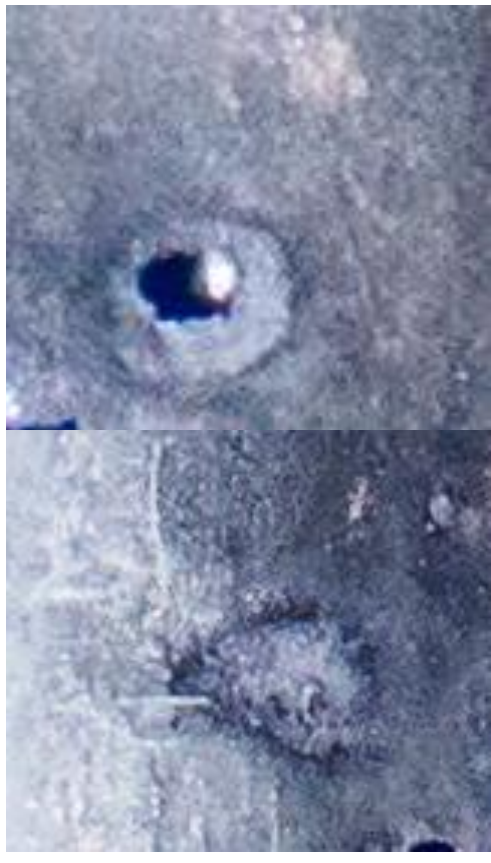

$a$

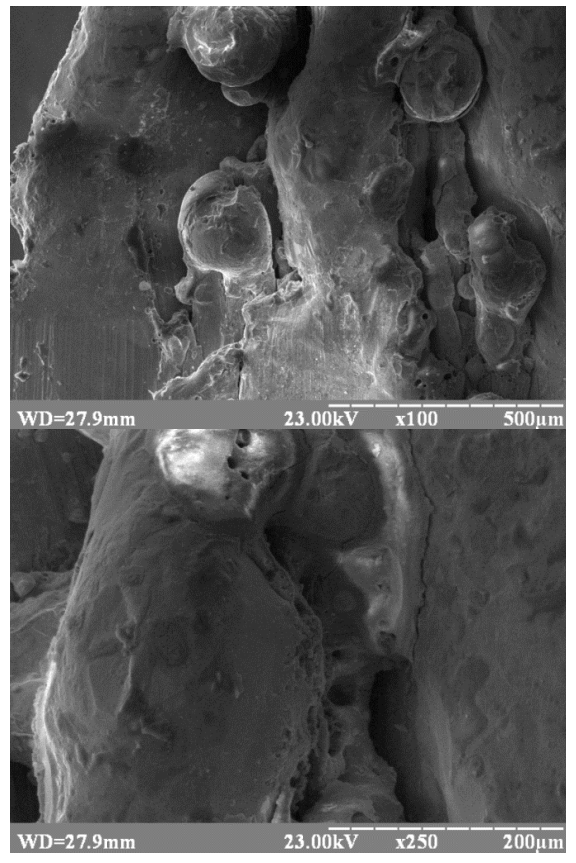

b

Fig. 5. Welding points: $a$ - heat-shielding module made of Ni-20Cr-6Al-1Ti- $1 \mathrm{Y}_{2} \mathrm{O}_{3}$ material; $b$ - microelectronic photo of the melt pool surface: upper example - welding with burn-through, $\varnothing 0.85 \mathrm{~mm}$; bottom example - satisfactory welding 

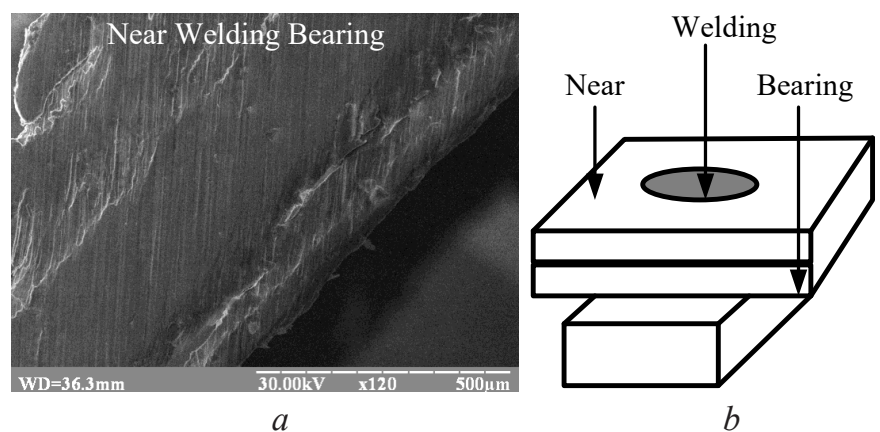

Fig. 6. Study of an element of the weld zone on a thin plate: $a$ - microelectronic photograph of the welding zones; $b$-diagram of welding zones

Table 3

Mass fraction of elements for various types of welding

\begin{tabular}{cccccccccc}
\hline & \multicolumn{3}{c}{ Laser welding } & \multicolumn{3}{c}{ Laser welding with APC } & \multicolumn{3}{c}{ Soldering process } \\
\cline { 2 - 10 } & Near & Welding & Bearing & Near & Welding & Bearing & Near & Welding & Bearing \\
\hline $\mathrm{C}$ & 24.3 & 15.81 & 4.79 & 33.8 & 12.1 & 4.79 & 57.25 & 52.16 & 7.75 \\
$\mathrm{O}$ & 4.6 & 3.05 & 6.67 & 4.6 & 17.4 & 16.7 & 34.96 & 34.96 & 2.51 \\
$\mathrm{Na}$ & 2.38 & 0.07 & 0.23 & 2.4 & - & - & - & - & - \\
$\mathrm{Al}$ & 2.76 & 5.72 & 6.63 & 1.7 & 22.1 & 16.6 & - & - & 6.16 \\
$\mathrm{~S}$ & 0.28 & 0.05 & 0.0 & - & - & - & - & - & - \\
$\mathrm{Cl}$ & 2.25 & 0.0 & 0.04 & - & - & - & - & - & - \\
$\mathrm{K}$ & 0.47 & 0.08 & 0.01 & - & 0.2 & - & 1.15 & 2.93 & - \\
$\mathrm{Ca}$ & 0.39 & 0.1 & 0.1 & - & - & - & 0.48 & 0.47 & - \\
$\mathrm{Ti}$ & 0.56 & 0.1 & 0.0 & - & 1.18 & - & 1.1 & 1.31 & - \\
$\mathrm{Cr}$ & 17.6 & 15.8 & 21.6 & 10.7 & 6.15 & 20.7 & 1.15 & 9.95 & 17.55 \\
$\mathrm{Ni}$ & 44.2 & 58.1 & 59.04 & 43.8 & 37.2 & 39.2 & 0.45 & - & 64.33 \\
$\mathrm{Y}$ & 0.21 & 1.12 & 0.89 & 0.4 & 0.8 & 1.9 & 1.1 & 0.2 & 1.9
\end{tabular}

The presence of oxygen at the points under study can be explained by the oxidation of a rather loose layer on the surfaces (Fig. 4), and this oxygen remains in the melt bath after the end of the process. Obviously, the use of laser welding provides better structural and elemental characteristics, since the absence of an atmosphere and local heating do not lead to significant changes in the base material in the area around the weld.

The use of brazing alloys as filler materials has a certain effect on the structure and quality of the formed weld, but requires further optimization of the process. In this case, only partial melting of one of the plates is possible, and with the use of additional ballasts, the process can be reduced to the process.

Subsequent mechanical tests of the resulting joint showed that the welded joint was destroyed by a static load perpendicular to the plane of formation of the weld point. It was found that the fault occurs mainly in the heat-affected zone, in the place of cracking.

It was noted that a significant decrease in the number of pulses (up to 5-10 per cycle) leads to the formation of a low strength joint, for which прочности $120 \mathrm{MPa}$ at $T=20^{\circ} \mathrm{C}$, although burnthrough of the weld was not observed.

Local heating of the workpiece prevents significant structural changes in the integrated elements, as well as their thermal deformation. At the same time, the resulting joint is susceptible to cracking with destruction of the contact zone upon application of a load of 30-40\% [ $\sigma$ ] (critical value) for the material, $\sigma_{b}=1005 \mathrm{MPa}, T=20^{\circ} \mathrm{C}$.

Comparison of the results of welding without filler metals and solder for BPr showed that the spread of adhesion strength at five points on ten samples is higher in welding with additives and amounts to $10-18 \%$. Relative elongation changes quite significantly, and decreases for welds 
with filler material to $\delta=1.3 \ldots 2.2 \%$ at operating temperature $\left(T=500{ }^{\circ} \mathrm{C}\right)(\mathbf{F i g} .7, \boldsymbol{a}-\boldsymbol{c})$. At the same time, overlapping welding of plates without additives made it possible to obtain (30-35\%) $\delta$ of the starting material. At a temperature of $T=20^{\circ} \mathrm{C}$, the relative elongations were large and amounted to $\delta=4.3 \ldots 9.1 \%$. Other mechanical characteristics remain practically unchanged and correspond to Table 2.
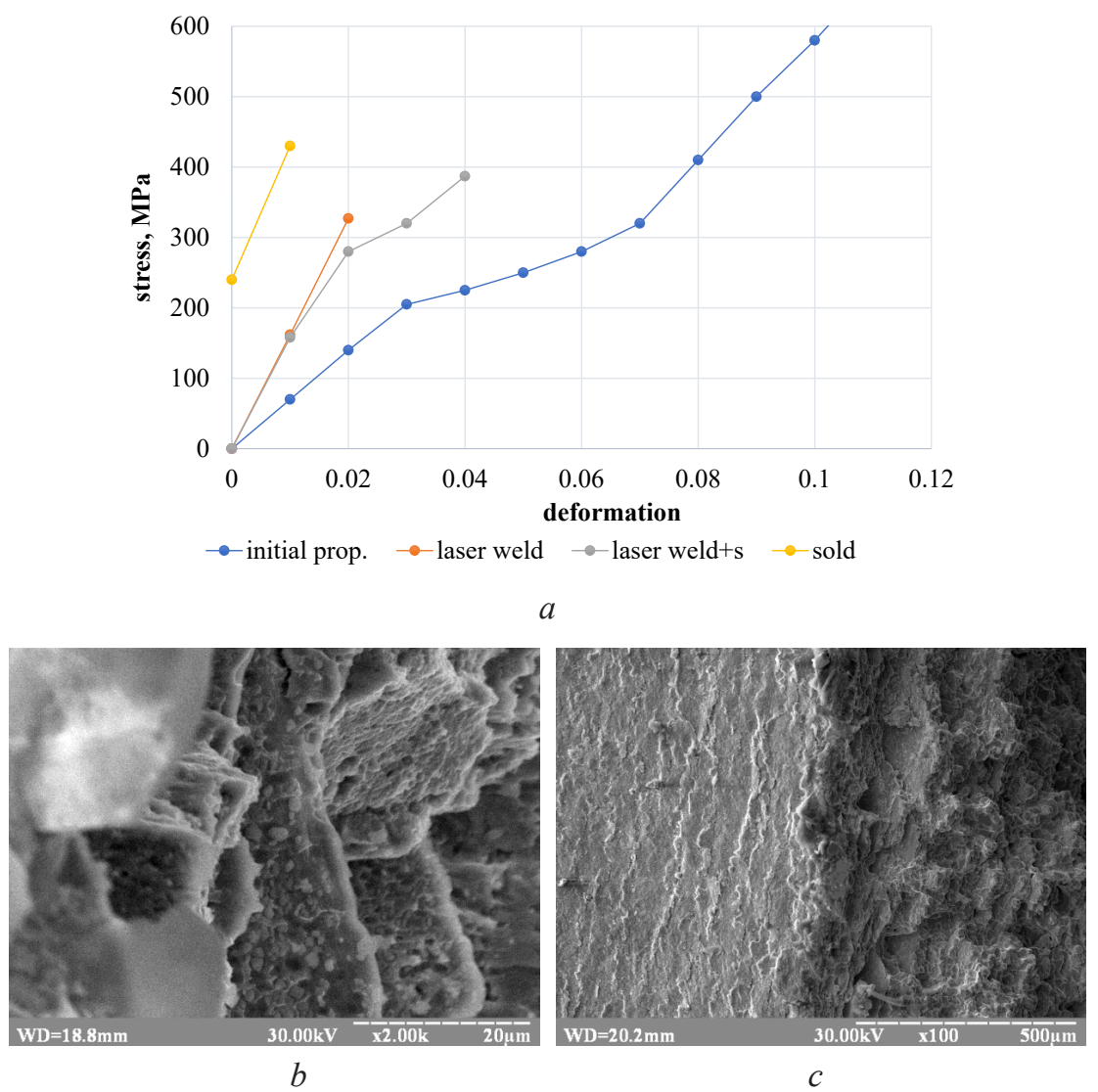

Fig. 7. Mechanical tests of the welding joint $\left(T=20^{\circ} \mathrm{C}\right)$ : $a$ - the results of mechanical tests; $b, c$ - fracture of a destroyed specimen obtained under static loading

Improving the process can improve these indicators, most likely by preventing the formation of a porous structure at the boundary of the melt pool and zones with microcracks.

It should be borne in mind that the initial billet from Ni-20Cr-6Al-Ti- $\mathrm{Y}_{2} \mathrm{O}$, obtained by powder metallurgy [11], is subsequently rolled into sheets of the required thickness $(0.4-0.14 \mathrm{~mm})$. In this case, changes in its structure and phases occur, the initial porosity decreases, and at the same time the amount of intermetallic compounds and oxides on the surface increases. This phenomenon worsens, and in some cases almost completely excludes weldability.

Electron microscopic studies have shown that there is a clearly defined dispersed structure in the Ni-20Cr-6Al-Ti- ${ }_{2} \mathrm{O}$ plates, and the surfaces of the two mating samples are practically identical. In Fig. 8, and the particles are on the order of 1-2 $\mu \mathrm{m}$; microvoids and cavities are observed in the surface layer. The entire investigated surface (Fig. 8, $\boldsymbol{b}, \boldsymbol{c}$ ) is covered with a network of microcracks. It can be assumed that the alloy contains a large amount of Ni-Al, intermetallic compounds with an ordered cubic body-centered crystal lattice. As a result, it was possible to consider such intermetallic compounds in some micrographs of the end parts of the plates. This explains a number of failures in obtaining a reliable welded joint in the traditional way.

Since the sintered dispersion-strengthened composite is prone to the formation of intermetallic inclusions that affect the mechanical properties of the material, further search for special methods of ensuring the welding process is required. 


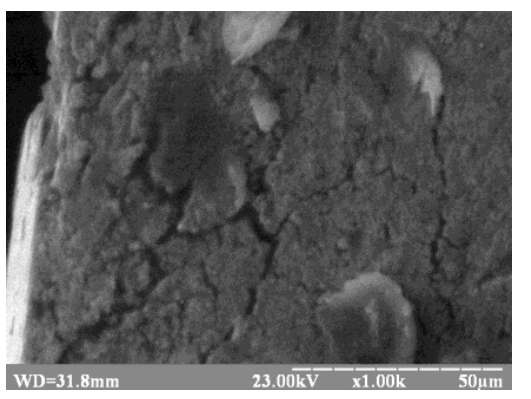

$a$

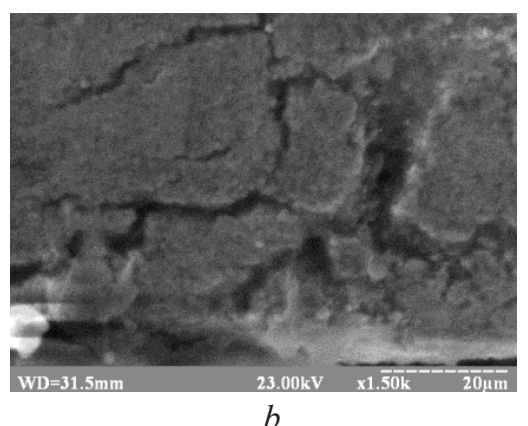

Fig. 8. Test samples:

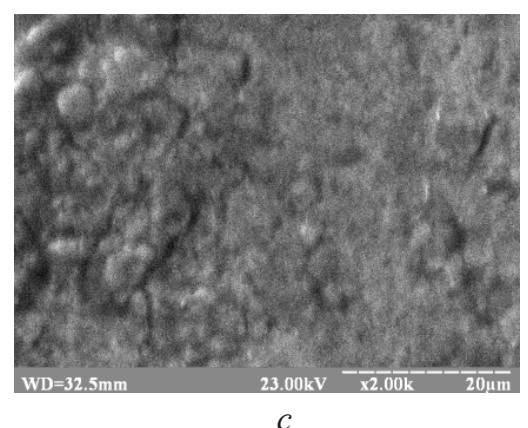

$a$-surface layer; $b, c$-end side of the workpiece with a thickness of $0.14 \mathrm{~mm}$

Another factor affecting the low weldability of elements into a single structure is the unevenness of the structural composition and oxide inclusions observed on the surface of the workpiece, apparently representing conglomerates of $\mathrm{Y}_{2} \mathrm{O}_{3}$. Rather large areas can be explained by incomplete mixing of nanoparticles and their tendency to form separate surface clusters. In such zones, thermodynamic instability can appear, and when exposed to heat, such foci cause an exothermic oxidation reaction of $\mathrm{Al}$, as a result of which burn-throughs and fistulas occur (for thinsheet blanks).

It becomes obvious that improving the quality of welding is possible both due to a more thorough preparation of the initial workpieces (alignment, heat treatment with the above modes, removal of surface contaminants and oxides), and due to optimization of the modes of welding in a vacuum chamber.

At the same time, the multicomponent composition of the composite, the presence of $\mathrm{Y}_{2} \mathrm{O}_{3}$ in its structure significantly limits the application of the proposed welding method, requires adaptation of the process for other heat-resistant materials.

It should be noted that in order to prevent cracking of the weld, further research should be aimed at ensuring a tight fit and high-quality contact connection of elements before welding. Another way to improve the quality of the joint is to increase the vacuum level to $10^{-3} \mathrm{~Pa}$, as well as to ensure the required cooling cycle of the workpiece. A promising method is high-frequency laser welding using screens and heat-removing elements (ballasts).

Thus, further research should be aimed at finding rational welding conditions, ensuring the required composition of the filler metal in the molten pool, as well as the formation of a continuous weld.

Improvements are also required in the vacuum chamber: using a drive system to move the work piece in a controlled manner will allow for a more stable welding process.

\section{Conclusions}

Mechanical tests of welded joints made by spot welding of powder dispersion-hardened alloy Ni-20Cr-6Al-Ti- $\mathrm{Y}_{2} \mathrm{O}_{3}$ are carried out. The possibility of using laser vacuum welding for the integration of thin-sheet elements in the design of heat-shielding systems is shown.

Welding points made in a vacuum chamber with a pressure of $10^{-2} \mathrm{~Pa}$ have through damage (due to the thickness of the plates - 0.1...0.14 mm and restrictions imposed on the use of a laser of this type) caused by exposure to a laser beam, and the diameter of the resulting holes is directly determined by the number of radiation pulses. A decrease in the number of pulses (up to 5-10 per cycle) leads to the formation of low-strength joints, for which Ni-20Cr-6Al-Ti- $\mathrm{Y}_{2} \mathrm{O}_{3} 120 \mathrm{MPa}$ at $T=20^{\circ} \mathrm{C}$. The maximum strength of the weld section for the contact area is achieved when the surface is irradiated with a defocused laser beam $\varnothing 0.7-0.8 \mathrm{~mm}$ with a pulse energy of $8 \mathrm{~J}$ and is $0.4-0.5\left[\sigma_{b}\right]$ strength of the base metal, or about $130-145 \mathrm{MPa}$ (at temperatures $T=500 \ldots 600{ }^{\circ} \mathrm{C}$ ). The destruction of the contact zone during mechanical tensile tests occurs according to the scheme of active cracking.

The presence of powdered solders in the melt pool (in the experiments, VPR-36 solder was used) reduces the change in the parameters of the formed welded joint and increases its crack 
resistance. Relative elongation of specimens welded with filler material is $\delta=1.3 \ldots .2 .2 \%$, without additives $-\delta=0.5 \ldots 1.1 \%\left(T=500 \ldots 600^{\circ} \mathrm{C}\right)$.

\section{Acknowledgement}

The work was carried out within the framework of project No. 607182 of the 7th European Framework Program for the creation of ultralight thermal protection structures.

The authors are grateful for the opportunity provided to carry out these studies in conjunction with the «Yuzhnoye» State Design Office (topic No. 384/17 «Manufacturing and welding of elements of the TPG model»). «Yuzhnoye» is a high-tech research and production center of Ukraine in the field of creation and production of spacecraft and launch vehicles, and for which these studies are relevant and significant. Special thanks to the Frantsevich Institute for Problems of Materials Science named of the National Academy of Sciences of Ukraine, which provided blanks, materials and powders for experimental research. We would also like to express our gratitude to the V. Bakul Institute for Superhard Materials for assistance in carrying out certain laboratory studies and tests.

\section{References}

[1] Husarova, I. O., Potapov, O. M., Manko, T. A., Falchenko, Y. V., Petrushintsev, L. V., Frolov, G. A., Soltsev, V. P. (2017). Problems of creations of reusable spacecraft heat protection. Technological Systems, 4 (81), 47-55. doi: https://doi.org/10.29010/081.6

[2] Uyanna, O., Najafi, H. (2020). Thermal protection systems for space vehicles: A review on technology development, current challenges and future prospects. Acta Astronautica, 176, 341-356. doi: https://doi.org/10.1016/j.actaastro.2020.06.047

[3] Lukin, V. I., Rylnikov, V. S., Afanasyev-Khodykin, A. N., Timofeyeva, O. B. (2013). Special features of diffusion welding of EP975 creep-resisting alloy and VKNA-4U cast single-crystal intermetallic alloy for blisk structures. Welding International, 28 (7), 562-567. doi: https://doi.org/10.1080/09507116.2013.840043

[4] Rai, R., Elmer, J. W., Palmer, T. A., DebRoy, T. (2007). Heat transfer and fluid flow during keyhole mode laser welding of tantalum, Ti-6Al-4V, 304L stainless steel and vanadium. Journal of Physics D: Applied Physics, 40 (18), $5753-5766$. doi: https://doi.org/10.1088/0022-3727/40/18/037

[5] Cai, C., Chen, H., Zhang, W. (2017). Research status and development prospects of laser welding under vacuum. Opto-Electronic Engineering, 44 (10), 945-952. Available at: http://www.oejournal.org/oej-data/oee/2017/10/PDF/gdgc-44-10-945.pdf

[6] Nawi, I. N., Saktioto, Fadhali, M., Hussain, M. S., Ali, J., Yupapin, P. P. (2011). Nd:YAG Laser Welding of Stainless Steel 304 for Photonics Device Packaging. Procedia Engineering, 8, 374-379. doi: https://doi.org/10.1016/j.proeng.2011.03.069

[7] Geng, Y., Akbari, M., Karimipour, A., Karimi, A., Soleimani, A., Afrand, M. (2019). Effects of the laser parameters on the mechanical properties and microstructure of weld joint in dissimilar pulsed laser welding of AISI 304 and AISI 420. Infrared Physics \& Technology, 103, 103081. doi: https://doi.org/10.1016/j.infrared.2019.103081

[8] Reisgen, U., Olschok, S., Jakobs, S., Turner, C. (2016). Laser beam welding under vacuum of high grade materials. Welding in the World, 60 (3), 403-413. doi: https://doi.org/10.1007/s40194-016-0302-3

[9] Salenko, A., Chencheva, O., Glukhova, V., Shchetynin, V., Budar, M. R. F., Klimenko, S., Lashko, E. (2020). Effect of slime and dust emission on micro-cutting when processing carbon-carbon composites. Eastern-European Journal of Enterprise Technologies, 3 (1 (105)), 38-51. doi: https://doi.org/10.15587/1729-4061.2020.203279

[10] Alnusirat, W. (2019). Application of Laser Radiation for Intensification of Chemical Heat Treatment. Lasers in Manufacturing and Materials Processing, 6 (3), 263-279. doi: https://doi.org/10.1007/s40516-019-0093-Z

[11] Salenko, O. F., Shchetynin, V. T., Lashko, E. E., Husarova, I. O., Solntsev, V. P., Sytnyk, O. O. (2018). Guaranteeing of the Mechanical Characteristics of Soldered Thin-Walled Structures of Ni-20Cr-6Al-1Ti- $1 \mathrm{Y}_{2} \mathrm{O}_{3}$ Refractory Alloy. Materials Science, 54 (2), 260-265. doi: https://doi.org/10.1007/s11003-018-011-4

Received date 10.07.2020

(C) The Author(s) 2021

Accepted date 07.07.2021

This is an open access article

Published date 13.09.2021

under the Creative Commons CC BY license

How to cite: Alnusirat, W., Salenko, A., Chencheva, O., Shlyk, S., Gusarova, I., Potapov, A. (2021). About the possibility of application of laser vacuum welding for the integration of elements of heat-protective structures from powder materials. EUREKA: Physics and Engineering, 5, 88-99. doi: https://doi.org/10.21303/2461-4262.2021.001998 